\title{
A Duopoly Manufacturers' Game Model Considering Green Technology Investment under a Cap-and-Trade System
}

\author{
Yi Zheng ${ }^{1}$, Gaoxun Zhang ${ }^{2, *}$ and Weiwei Zhang ${ }^{3}$ \\ 1 Department of Industrial Engineering, School of Management, Xihua University, Chengdu 610039, China; \\ zhengyi@mail.xhu.edu.cn \\ 2 School of Science, Southwest University of Science and Technology, Mianyang 621010, China \\ 3 School of Management, Xihua University, Chengdu 610039, China; zhangweiwei@mail.xhu.edu.cn \\ * Correspondence: zhanggaoxun@swust.edu.cn.com
}

Received: 13 January 2018; Accepted: 1 March 2018; Published: 5 March 2018

\begin{abstract}
This research studied the duopoly manufacturers' decision-making considering green technology investment and under a cap-and-trade system. It was assumed there were two manufacturers producing products which were substitutable for one another. On the basis of this assumption, the optimal production capacity, price, and green technology investment of the duopoly manufacturers under a cap-and-trade system were obtained. The increase or decrease of the optimal production quantity of the duopoly manufacturers under a cap-and-trade system was decided by their green technology level. The increase of the optimal price as well as the increase or decrease of the maximum expected profits were decided by the initial carbon emission quota granted by the government. Our research indicates that the carbon emission of unit product is inversely proportional to the market share of an enterprise and becomes an important index to measure the core competitiveness of an enterprise.
\end{abstract}

Keywords: cap-and-trade; green technology investment; duopoly; game theory

\section{Introduction}

Global warming has posed a serious threat to the global ecosystem and the survival of humans [1]. Research findings show that at least $90 \%$ of global warming is attributable to human activities [2]. In order to alleviate global warming, the USA, Canada, and many other countries around the world have enacted legislation or designed mechanisms to curb carbon emissions, such as the European Union Emission Trading System and the Kyoto Protocol. Giant retailer Wal-Mart purchases products that are sustainable. The cap-and-trade system is also considered when Wal-Mart purchases products in order to promote greening. From the government perspective, the commonly used energy-saving and emission-reducing policies include the carbon cap, carbon cap-and-trade, and carbon tax [3]. Among them, carbon cap-and-trade policy, giving full play to the role of both administrative control and market trade, has been considered as the most effective means and even the top choice for governments throughout the world [4]. From the perspective of enterprises, which, in order to meet the requirements of government's carbon-emission policies, can invest in green technology to reduce their carbon emission, green investment means reducing the carbon footprint of unit product and increasing the green competitiveness of enterprises through the input of relative resources such as human resources and financial resources. In this way, the price war between enterprises is turned into a competition to protect the environment through green technology. The implementation of government carbon emission policies together with enterprises' countermeasures has increased the complexity of the corporate operation decision-making, which has actually become an issue requiring urgent 
solution. Considering the status quo, this paper, combining governments' carbon regulation policies and enterprises' emission-reducing countermeasures, which themselves integrate governments' carbon emission policies, carbon emission per unit product, and enterprises' green technology investments, conducts a theoretical research of the operation strategies adopted by enterprises investing in green technologies in response to a cap-and-trade system.

The literature related to this research mainly focuses on two aspects, namely, manufacturers' operational decision-making under the competitive environment and enterprises' operational decisionmaking under a cap-and-trade system. In terms of the manufacturer's operational decision-making under the competitive environment, scholars proceeded from two perspectives-competition among manufacturers under the supply chain environment and competition among manufacturers in the parallel market. Zhang et al. [5], Shi et al. [6], and Xiao et al. [7] concentrated on studying the competition between manufacturers and suppliers and manufacturers and consumers under the supply chain environment. Zhao D.Z. et al. [8] studied a two-level supply chain consisting of two manufacturers and one dominant retailer under a cap-and-trade system, in which the retailer stimulated the two manufacturers to join in its efforts to cut emission through low-carbon publicity. By doing so, they achieved the optimal emission reduction for each manufacturer and the optimal publicity for the retailer and realized the retailer-manufacturer joint emission reduction in the supply chain. Choi [9] studied the price in different channel structures made up of multiple manufacturers and multiple retailers in the supply chain. Geffen and Rothenberg [10] found out, through a case study, that, for the sake of improving environmental performance, competition, cooperation and coordination of enterprises in the supply chain can maximally enhance the strategic partnership between suppliers and manufacturers in the supply chain. Klassen and Vachon pointed out that competition and cooperation between manufacturers and suppliers in the supply chain could drive more investments in green technologies. Later, Klassen [11] and Vachon [12] deepened the former research by investigating the environment-dependent supply chain in the Chinese market. Their survey results indicated a positive influence of environmental protection cooperation on environmental improvement and production performance improvement. In terms of parallel competition of manufacturers, Moorthy [13] and Banker [14] explored the quality and price competition mechanisms between two enterprises of the same nature and found the correlation between quality and competition parameters obtaining the equilibrium strategy for each enterprise. Wu et al. [15] discussed the optimal price strategy for two retailers in a two-stage supply chain. So [16] analyzed the multi-enterprise competitive equilibrium and the optimal strategy for every enterprise by assuming the demand to be both price-sensitive and delivery time-sensitive. Chen et al. [17] studied the optimal pricing and production strategy under the carbon tax policy for two competitors in a parallel market featuring power equilibrium. $\mathrm{Wu}$ Yin et al. [18] conducted a research of the competition among new products, remanufactured products by manufacturers, and remanufactured products by remanufacturers to learn the influence of the production cost of new products on manufacturers and remanufacturers. All the above research considered the competition between two enterprises in the parallel market but failed to pay attention to enterprise competition under the low-carbon environment.

Research into enterprise operational decision-making under a cap-and-trade system mainly proceeds from the single enterprise environment and the supply chain environment. Under the single enterprise environment, Hua et al. [19] studied how single enterprises in the market should manage their carbon footprint of their inventory and they obtained the optimal order quantity of enterprises under a cap-and-trade system. Furthermore, they used a theoretical analysis and a numerical analysis to examine the influence of carbon trade, carbon trade price, and carbon cap on order decision-making, carbon emission, and total cost. He et al. [20], under a cap-and-trade system, studied the issue of enterprise production lot size planning based on the Economic Order Quantity (EOQ) model, and they obtained the optimal production lot size for enterprises under a cap-and-trade system. Besides, they analyzed the influence of the cap-and-trade system on the optimal production lot size and the carbon emission. Wahab et al. [21] considered a two-level supply chain 
composed of one supplier and one retailer and built the EOQ model, targeting cost minimization under a carbon cap-and-trade system. Based on the EOQ model built, they came up with the optimal order strategy for the retailer. Xie X.P. and Zhao D.Z. [22] studied the emission reduction effects and profits under three conditions (noncooperation, semi-cooperation, and all-around cooperation) between the upstream and downstream companies considering a cap-and-trade system and analyzed how enterprises influenced each other during the emission reduction process and how carbon trade price influenced the carbon emission effects. Du et al. [23] considered a two-level supply chain consisting of one carbon emission enterprise and one carbon emission right supplier under a cap-and-trade system and used the non-cooperation game theory to design a mechanism to realize supply chain coordination and collaboration. Tseng et al. [24], considering the social cost of carbon emission, studied the strategic decision-making model for the sustainable supply chain under a cap-and-trade system. Yalabik et al. [25], considering consumer choices and government regulation, studied enterprise investment decision-making of environmentally friendly products. Their research findings showed that, when consumers were sensitive to carbon emission, enterprises would have the momentum to invest in green technologies to cut carbon emissions. Jiang et al. [26] examined the production quantity and green technology investment joint decision-making for a carbon emission enterprise faced with random demands under a cap-and-trade system and uncovered the influence of carbon emission policies on profits, carbon emissions, investment amounts, and investment opportunities. Toptal et al. [27] studied the purchase and green technology investment joint decision-making under three carbon emission reduction policies (carbon cap, carbon tax, and carbon cap-and-trade) and compared the influence of these three policies on enterprises' optimal order quantity and green technology investment policies.

From the above literature review, it can be seen that research into the manufacturer operational decision-making considering competition, either from the perspective of the supply chain or from the perspective of the horizontal market, failed to consider the low-carbon manufacturing environment, and that research into a cap-and-trade system considering green technology investment, mainly concentrated on the single manufacturer operational decision-making or the enterprise decision-making under the one-by-one supply chain environment, but ignored the enterprise decision-making decision under the manufacturer competitive environment. In order to fill these research gaps, this paper considered duopoly manufacturers under a cap-and-trade system and studied how duopoly manufacturers conducted green technology investment, production quantity, and price and carbon trade joint decision-making. This research was devoted to solving three problems: (1) how duopoly manufacturers should make decisions considering green technology investment and under a cap-and-trade system; (2) how green technology investment would influence the optimal decision-making and the maximum expected profits of duopoly manufacturers considering green technology investment and under a cap-and-trade system (compared with the situation in which green technology investment is not considered); and (3) how a cap-and-trade system would influence the optimal decision-making and the maximum expected profits of duopoly manufacturers considering the cap-and-trade system (compared with the situation in which the cap-and-trade system is not considered).

The major contributions of this research are reflected in the following three aspects: (1) expansion of the manufacturer operational decision-making research to the low-carbon context, thus enriching the manufacturer operation and management theory and providing research strategies for a follow-up research combining the manufacturer competition and the low-carbon environment; (2) expansion of the single-manufacturer research perspective widely adopted by the current research about low-carbon manufacturing to a two-manufacturer perspective, thus making the research scenario closer to practices and the research findings more operational and guiding relevant enterprises to conduct scientific decision-making; (3) comparison of the manufacturer operational decision-making considering and not considering the cap-and-trade system, thus providing references for government's policy formulation. 


\section{Question Description and Hypotheses}

This paper considered two manufacturers' products which were substitutable for one another, and conducted green technology investment, product capacity, and sales price decision-making under a cap-and-trade system. These two manufacturers were financially equal in the market, and their decision-making happened simultaneously. At the beginning of the production process, the two manufacturers could obtain the free carbon emission cap from the government. The initial cap, decided by the government, was not within the scope of this research. During the production process, the enterprises can decide whether to invest in green technologies or not. By investing in green technologies or purchasing carbon emission quota from the market, the enterprises can make their carbon emission comply with the government's policy requirements. If, at the end of the production process, the enterprises have not used up their carbon emission cap, they can trade the remaining quota on the market. Therefore, the two manufacturers involved in this research had to decide their production quantity, retail price, green technology investment amount, and carbon trade volume. It was assumed that there were two manufacturers, Manufacturer 1 (M1) and Manufacturer 2 (M2). The corresponding decision-making variables and parameters of the two manufacturers are marked with the subscript 1 and 2, respectively.

Table 1 are the definitions of the symbols used in this paper:

Table 1. Summary of Notations.

\begin{tabular}{cl}
\hline Symbols & \multicolumn{1}{c}{ Definitions } \\
\hline$q_{1}, q_{2}$ & $\begin{array}{l}\text { Production quantity of the two manufacturers/Market demand quantity of the } \\
\text { two products; }\end{array}$ \\
\hline$p_{1}, p_{2}$ & Retail price of the two products; \\
\hline$e x_{1}, e x_{2}$ & Carbon emission quota trading volume of the two manufacturers in the market; \\
\hline$c_{1}, c_{2}$ & Unit production cost of the two manufacturers; \\
\hline$\rho_{1}, \rho_{2}$ & $\begin{array}{l}\text { Clean coefficient (percentage of unit product carbon emission reduction). } \\
\text { If } \rho_{1}, \rho_{2}=0, \text { it means the the two manufacturers do not invest in green technologies; }\end{array}$ \\
\hline$C_{1}\left(\rho_{1}\right), C_{2}\left(\rho_{2}\right)$ & Green technology investment cost; \\
\hline$e_{1}, e_{2}$ & $\begin{array}{l}\text { Unit product carbon emission amount of manufacturers not investing in } \\
\text { green technologies; }\end{array}$ \\
\hline$A_{1}, A_{2}$ & Initial carbon emission cap of the two manufacturers; \\
\hline$w$ & Market trading price of unit carbon emission right; \\
\hline$\pi_{1}, \pi_{2}$ & Expected profits of the two manufacturers. \\
\hline
\end{tabular}

In order to better reveal the essence or make the model more reasonable, this paper made the following hypotheses:

(1) H1: The demand is certain and expressed as $p_{i}=\alpha-\beta q_{i}-\gamma q_{j}(i, j=1,2 ; i \neq j)$. In this way, two decision-making variables, namely, the production quantity and the retail price, of the two manufacturers can be simplified into one decision-making variable, that is, production quantity.

(2) H2: The green technology cost of the manufacturers is related to the clean coefficient, $\rho$, and $C_{i}^{\prime}\left(\rho_{i}\right)>0, C_{i}^{\prime \prime}\left(\rho_{i}\right)>0$, and $C_{i}^{\prime}\left(\rho_{i}\right) \geq C_{i}^{\prime}(0)(i=1,2)$. Besides, the clean coefficient is a quadratic function, $C_{i}\left(\rho_{i}\right)=\frac{1}{2} \delta_{i} \rho_{i}^{2}$, and the green technology investment is a one-off investment and is free from the influence of production quantity. In this hypothesis, the green technology investment decision-making is expressed as the clean coefficient decision-making.

(3) H3: $p_{i}>c_{i}+w e_{i}>0, i=1$, 2. This hypothesis guarantees that manufacturers can still make profits by selling products even without investing in green technologies.

(4) H4: $\beta>\gamma>0$. This hypothesis suggests that every product is more sensitive to its own retail price than to the retail price of its substitute. 
The sequence of event in this research is as below:

First, the government granted every manufacturer a free initial carbon emission cap. Second, the two manufacturers decided simultaneously and confirmed their respective production quantity, sales price, green technology investment amount, and trade trading volume. Third, the consumers' demands were satisfied, and the manufacturers made profits.

\section{Manufacturers' Decision-Making under Nash Equilibrium}

The carbon emission trading volume between the manufacturers and the external market can be expressed as:

$$
e x_{i} \equiv e\left(1-\rho_{i}\right) q_{i}-A_{i}
$$

where $e x_{i}$ is the cost of $M_{i}$ paid for purchasing carbon emission quota after green technology investment. If it is negative, it means that $M_{i}$ is selling its carbon emission quota to the external market to make profits; if it is zero, it means that $M_{i}$ is not trading its carbon emission quota with the external market.

The profit function of the two manufacturers can be expressed as below:

$$
\pi_{i}\left(q_{i}, p_{i}, \rho_{i}\right)=\left(p_{i}-c_{i}\right) q_{i}-\frac{1}{2} \delta_{i} \rho_{i}^{2}-w\left[e_{i}\left(1-\rho_{i}\right) q_{i}-A_{i}\right] i, j=1,2 \text { and } i \neq j
$$

The first item of Equation (2) stands for the unit product marginal profit of the manufacturers; the second item stands for the green technology investment amount; the third item stands for the income or cost for the manufacturers in the carbon emission trading.

Proposition 1. Under a carbon cap-and-trade system and considering green technology investment, the duopoly manufacturers' game has only Nash equilibrium solution. Under Nash equilibrium, the clean coefficient $\left(\rho_{i}^{*}\right)$ and production quantity $\left(q_{i}^{*}\right)$ decision-making can be expressed as below, respectively:

$$
\begin{gathered}
\rho_{i}^{*}=\frac{w e_{i}\left(2 \beta \delta_{j}-w^{2} e_{j}^{2}\right)\left(\alpha-c_{i}-w e_{i}\right)-w e_{i} \delta_{j} \gamma\left(\alpha-c_{j}-w e_{j}\right)}{w^{4} e_{i}^{2} e_{j}^{2}-2 \beta w^{2}\left(\delta_{i} e_{j}^{2}+\delta_{j} e_{i}^{2}\right)+\delta_{i} \delta_{j}\left(4 \beta^{2}-\gamma^{2}\right)} \\
q_{i}^{*}=\frac{\delta_{i}\left(2 \beta \delta_{j}-w^{2} e_{j}^{2}\right)\left(\alpha-c_{i}-w e_{i}\right)-\delta_{i} \delta_{j} \gamma\left(\alpha-c_{j}-w e_{j}\right)}{w^{4} e_{i}^{2} e_{j}^{2}-2 \beta w^{2}\left(\delta_{i} e_{j}^{2}+\delta_{j} e_{i}^{2}\right)+\delta_{i} \delta_{j}\left(4 \beta^{2}-\gamma^{2}\right)}
\end{gathered}
$$

where, $i, j=1,2$ and $i \neq j$.

Prove. Considering that the demand is certain, $p_{i}=\alpha-\beta q_{i}-\gamma q_{j}$ is substituted into the profit function, and the partial derivative of $q_{i}$ and $\rho_{i}$ is worked out. Below are conditions for the first-order Nash equilibrium of the model $(i, j=1,2 ; i \neq j)$ :

$$
\begin{gathered}
\frac{\partial \pi_{i}\left(q_{i}, \rho_{i}\right)}{\partial q_{i}}=\alpha-2 \beta q_{i}-\gamma q_{j}-c_{i}-w e_{i}\left(1-\rho_{i}\right)=0 \\
\frac{\partial \pi_{i}\left(q_{i}, \rho_{i}\right)}{\partial \rho_{i}}=-\delta_{i} \rho_{i}+w e_{i} q_{i}=0
\end{gathered}
$$

The only Nash equilibrium solution of the above question can be obtained by solving the above equation set. The clean coefficient and production quantity of manufacturers under Nash equilibrium are shown in Equation (3). Substitute $q_{i}(i=1,2)$ into the demand function to obtain the optimal price $\left(p_{i}^{*}\right)$ of the manufacturers $\left(M_{i}\right)$ :

$$
p_{i}^{*}=\frac{\delta_{i} \beta\left(2 \beta \delta_{j}-w^{2} e_{i}^{2}\right)\left(\alpha+c_{i}+w e_{i}\right)-\delta_{i} \delta_{j} \gamma^{2}\left(c_{i}+w e_{i}\right)+\delta_{j} \gamma\left(w^{2} e_{i}^{2}-\beta \delta_{i}\right)\left(\alpha-c_{j}-w e_{j}\right)+\alpha w^{2} e_{i}^{2}\left(w^{2} e_{j}^{2}-2 \beta \delta_{j}\right)}{w^{4} e_{i}^{2} e_{j}^{2}-2 \beta w^{2}\left(\delta_{i} e_{j}^{2}+\delta_{j} e_{i}^{2}\right)+\delta_{i} \delta_{j}\left(4 \beta^{2}-\gamma^{2}\right)}(i, j=1,2 ; i \neq j) .
$$

Substitute $q_{i}$ and $\rho_{i}$ into Equation (1) to obtain the optimal carbon emission trading volume (ex $\left.x_{i}^{*}\right)$ of the manufacturers $\left(M_{i}\right): e x_{i}^{*}=e_{i}\left(1-\rho_{i}^{*}\right) q_{i}^{*}-A_{i}^{*}$. 
Proposition 1 suggests that, in the duopoly market environment, the two manufacturers, considering a cap-and-trade system and green technology investment, have the only Nash equilibrium solution. From Proposition 1, it can be observed that the optimal production quantity, the optimal product price, and the optimal clean coefficient of the two manufacturers are all irrelevant to the carbon emission cap $\left(A_{1}\right.$ and $\left.A_{2}\right)$.

Substitute $\rho_{i}^{*}, q_{i}^{*}$, and $p_{i}^{*}$ into the profit function of the manufacturers $\left(M_{i}\right)$. Then, the maximum expected profits of the two manufacturers can be obtained: $\pi_{i}\left(q_{i}^{*}, p_{i}^{*}, \rho_{i}^{*}\right)=\left(p_{i}^{*}-c_{i}\right) q_{i}^{*}-\frac{1}{2} \delta_{i} \rho_{i}^{* 2}-$ $w\left[e\left(1-\rho_{i}^{*}\right) q_{i}^{*}-A_{i}\right] i, j=1,2 ; i \neq j$. Based on the discussion of the maximum expected profits of the two manufacturers, the following proposition can be obtained:

Proposition 2. (1) $\pi_{i}\left(q_{i}^{*}, p_{i}^{*}, \rho_{i}^{*}\right)$ increases progressively with $A_{i}$.

(2) When ex $x_{i}^{*}<0, \pi_{i}\left(q_{i}^{*}, p_{i}^{*}, \rho_{i}^{*}\right)$ increases progressively with $w$; when ex $x_{i}^{*}=0, \pi_{i}\left(q_{i}^{*}, p_{i}^{*}, \rho_{i}^{*}\right)$ remains unchanged with $w$; when $x_{i}^{*}<0, \pi_{i}\left(q_{i}^{*}, p_{i}^{*}, \rho_{i}^{*}\right)$ decreases progressively with $w$.

Prove. (1) According to the Envelop Theorem, $\frac{d \pi_{i}\left(q_{i}^{*}, p_{i}^{*}, \rho_{i}^{*}\right)}{d A_{i}}=w>0$. It can be seen that $\pi_{i}\left(q_{i}^{*}, p_{i}^{*}, \rho_{i}^{*}\right)$ increases progressively with $A_{i}$;

(2) According to the Envelop Theorem, $\frac{d \pi_{i}\left(q_{i}^{*}, p_{i}^{*}, \rho_{i}^{*}\right)}{d w}=-\left[e\left(1-\rho_{i}^{*}\right) q_{i}^{*}-A_{i}\right]=-e x_{i}^{*}$ can be obtained. It can be seen that, when $e x_{i}^{*}<0$ and $\frac{d \pi_{i}\left(q_{i}^{*}, p_{i}^{*}, \rho_{i}^{*}\right)}{d w}>0, \pi_{i}\left(q_{i}^{*}, p_{i}^{*}, \rho_{i}^{*}\right)$ increases progressively with $w$. Similarly, when $e x_{i}^{*}=0, \pi_{i}\left(q_{i}^{*}, p_{i}^{*}, \rho_{i}^{*}\right)$ remains unchanged with $w$; when $e x_{i}^{*}<0, \pi_{i}\left(q_{i}^{*}, p_{i}^{*}, \rho_{i}^{*}\right)$ decreases progressively with $w$.

Proposition 2 suggests that the optimal profits of duopoly manufacturers, considering a cap-and-trade system and green technology investment, are positively correlated with their respective initial free carbon emission caps granted by the government. In other words, the higher the initial free carbon emission cap granted, the higher the optimal profits made; conversely, the lower the carbon emission caps, the lower the optimal profits. Proposition 2 also suggests that the changes of the optimal profits of duopoly manufacturers along with the unit carbon emission quota trading price are related to their carbon emission quota trading status. At the end of production, the manufactures can sell their remaining carbon emission quota if any. Then, the higher the unit carbon emission quota trading price is, the higher the optimal profits of duopoly manufacturers will be. If the initial carbon emission cap just serves the whole production process, the manufacturers will conduct no carbon emission quota trading. In this situation, the optimal profits of duopoly manufacturers are irrelevant to the unit carbon emission quota trading price. If the manufacturers need to purchase the carbon emission quota from the external market to meet the government's carbon emission requirements at the end of their production, the higher the unit carbon emission quota trading price is, the lower the optimal profits of duopoly manufacturers will be.

\section{Analysis of the Influence of Green Technology Investment on Decision-Making}

In order to analyze the influence of green technology investment on duopoly manufacturers' decision-making, this part of our study first supposes that the manufacturers are under a cap-and-trade system but do not decide to invest in green technologies. In this situation, the expected profit function of duopoly manufacturers can be expressed as reported below: (The superscript $c$ is used to distinguish from other situations)

$$
\pi_{i}^{c}\left(q_{i}, p_{i}\right)=\left(p_{i}-c_{i}\right) q_{i}-w\left(e_{i} q_{i}-A_{i}\right) i, j=1,2 ; i \neq j
$$

Substitute $p_{i}=\alpha-\beta q_{i}-\gamma q_{j}$ into Equation (5) for simplification, and the profit function of manufacturers (Mi) can be obtained: $\pi_{i}^{c}\left(q_{i}\right)=\left(\alpha-\beta q_{i}-\gamma q_{j}-c_{i}\right) q_{i}-w\left[e_{i} q_{i}-A_{i}\right] i, j=1,2 ; i \neq j$.

Concerning the optimal decision-making policy of duopoly manufacturers under a cap-and-trade system but not considering green technology investment, the following proposition can be made: 
Proposition 3. Duopoly manufacturers' game under a cap-and-trade system but not considering green technology investment have the only Nash equilibrium solution. Under Nash equilibrium, production capacity and price decision-making of the manufacturers can be expressed, respectively, as shown below:

$$
\begin{gathered}
q_{i}^{c *}=\frac{2 \beta\left(\alpha-c_{i}-w e_{i}\right)-\gamma\left(\alpha-c_{j}-w e_{j}\right)}{4 \beta^{2}-\gamma^{2}} i, j=1,2 \text { and } i \neq j \\
p_{i}^{c *}=\frac{2 \beta^{2}\left(\alpha+c_{i}+w e_{i}\right)-\gamma^{2}\left(c_{i}+w e_{i}\right)-\beta \gamma\left(\alpha-c_{j}-w e_{j}\right)}{4 \beta^{2}-\gamma^{2}} i, j=1,2 \text { and } i \neq j
\end{gathered}
$$

Prove. Assuming that $\frac{d \pi_{i}^{c}\left(q_{i}\right)}{d q_{i}}=\alpha-2 \beta q_{i}-\gamma q_{j}-c_{i}-w e_{i}=0$, the reaction function of the two manufacturers can be obtained, $q_{i}=\frac{\alpha-c_{i}-w e_{i}}{2 \beta}-\frac{\gamma}{2 \beta} q_{j} i, j=1,2 ; i \neq j$. Solve the above two equations simultaneously to obtain the optimal production quantity $q_{i}^{c *}=\frac{2 \beta\left(\alpha-c_{i}-w e_{i}\right)-\gamma\left(\alpha-c_{j}-w e_{j}\right)}{4 \beta^{2}-\gamma^{2}}$ and $p_{i}^{c *}=\frac{2 \beta^{2}\left(\alpha+c_{i}+w e_{i}\right)-\gamma^{2}\left(c_{i}+w e_{i}\right)-\beta \gamma\left(\alpha-c_{j}-w e_{j}\right)}{4 \beta^{2}-\gamma^{2}}$. Substitute $q_{i}^{c *}$ and $p_{i}^{c *}$ into the profit function of the manufacturers to obtain the expected profits of the manufacturers under Nash equilibrium, $\pi_{i}^{c *}\left(q_{i}^{c *}, p_{i}^{c *}\right)=\left(p_{i}^{c *}-c_{i}\right) q_{i}^{c *}-w\left(e_{i} q_{i}^{c *}-A_{i}\right)$.

In order to guarantee that the optimal solution of the manufacturers is meaningful, it is necessary to guarantee $q_{i}^{c *}>0(i=1,2)$, namely, $2 \beta\left(\alpha-c_{i}-w e_{i}\right)-\gamma\left(\alpha-c_{j}-w e_{j}\right)>0 i, j=1,2$ and $i \neq j$. The model parameters obtained through solving the equation should meet the condition of $\frac{\gamma}{2 \beta}<\frac{\alpha-c_{i}-w e_{i}}{\alpha-c_{j}-w e_{j}}<\frac{2 \beta}{\gamma} i, j=1,2$ and $i \neq j$ to guarantee that the Nash equilibrium solution is meaningful. This paper assumes that the condition is tenable all the time.

Proposition 3 suggests that the duopoly manufacturers' game, under a cap-and-trade system but not considering green technology investment, has the only Nash equilibrium solution. The optimal production quantity and price of the manufacturers is irrelevant to the initial carbon emission cap granted by the government, but relevant to the carbon emission trading price.

Proposition 4. When model parameters meet the condition of $w^{4} e_{i}^{2} e_{j}^{2}>2 \beta w^{2}\left(\delta_{i} e_{j}^{2}+\delta_{j} e_{i}^{2}\right), q_{i}^{*}<q_{i}^{c *}$.

Prove. When $w^{4} e_{i}^{2} e_{j}^{2}>2 \beta w^{2}\left(\delta_{i} e_{j}^{2}+\delta_{j} e_{i}^{2}\right), w^{4} e_{i}^{2} e_{j}^{2}-2 \beta w^{2}\left(\delta_{i} e_{j}^{2}+\delta_{j} e_{i}^{2}\right)>0$ and $q_{i}^{*}>$ $\frac{2 \beta\left(\alpha-c_{i}-w e_{i}\right)-\gamma\left(\alpha-c_{j}-w e_{j}\right)-\frac{w^{2} e_{j}^{2}}{\delta_{j}}\left(\alpha-c_{i}-w e_{i}\right)}{4 \beta^{2}-\gamma^{2}}>\frac{2 \beta\left(\alpha-c_{i}-w e_{i}\right)-\gamma\left(\alpha-c_{j}-w e_{j}\right)}{4 \beta^{2}-\gamma^{2}}=q_{i}^{c *}$.

Proposition 4 suggests that the optimal production quantity of the manufacturers, under certain parameters and not considering green technology investment, is higher than the optimal production quantity of the manufacturers considering green technology investment.

\section{Analysis of the Influence of a Cap-and-Trade System on Decision-Making}

In order to analyze the influence of the cap-and-trade system on optimal decision and maximum expected profits of duopoly manufacturers, this part of our study compared the conclusions drawn with and without a cap-and-trade system. Under the condition without a cap-and-trade system, there is no limit on the carbon emissions of the two manufacturers, so they do not have the motivation to invest in green technologies, and their expected profit function can be expressed as reported below:

$$
\pi_{i}^{n}\left(q_{i}, p_{i}\right)=\left(p_{i}-c_{i}\right) q_{i} i, j=1,2 \text { and } i \neq j
$$

Substitute $p_{i}=\alpha-\beta q_{i}-\gamma q_{j}$ into Equation (8) for simplification and obtain the profit function of the manufacturers $(\mathrm{Mi}), \pi_{i}^{n}\left(q_{i}\right)=\left(\alpha-\beta q_{i}-\gamma q_{j}-c_{i}\right) q_{i} i, j=1,2 ; i \neq j$. Suppose $\frac{d \pi_{i}^{n}\left(q_{i}\right)}{d q_{i}}=$ $\alpha-2 \beta q_{i}-\gamma q_{j}-c_{i}=0$ and the response function of the two manufacturers $\left(M_{i}\right)$ can be obtained $q_{i}=\frac{\alpha-c_{i}}{2 \beta}-\frac{\gamma}{2 \beta} q_{j} i, j=1,2 ; i \neq j$. Solve the two equations simultaneously to obtain the optimal 
production quantity decision-making of the manufacturers (Mi): $q_{i}^{n *}=\frac{2 \beta\left(\alpha-c_{i}\right)-\gamma\left(\alpha-c_{j}\right)}{4 \beta^{2}-\gamma^{2}}$ and $p_{i}^{n *}=$ $\frac{2 \beta^{2}\left(\alpha+c_{i}\right)-\gamma^{2} c_{i}-\beta \gamma\left(\alpha-c_{j}\right)}{4 \beta^{2}-\gamma^{2}}$. In order to guarantee the optimal solution to be meaningful, it is assumed that $q_{i}^{n *}>0(i=1,2)$, namely, $2 \beta\left(\alpha-c_{i}\right)-\gamma\left(\alpha-c_{j}\right)>0$ and $2 \beta\left(\alpha-c_{j}-w e_{j}\right)-\gamma\left(\alpha-c_{i}-w e_{i}\right)>0$ $(i, j=1,2$ and $i \neq j)$. The model parameters worked out should meet the condition of $\frac{\gamma}{2 \beta}<\frac{\alpha-c_{i}}{\alpha-c_{j}}<$ $\frac{2 \beta}{\gamma} i, j=1,2$ and $i \neq j$, so as to guarantee that the Nash equilibrium solution is meaningful. This paper assumed that the above condition is tenable all the time, and the expected profit function of the manufacturers under Nash equilibrium can be obtained: $\pi_{i}^{n *}\left(q_{i}^{n *}, p_{i}^{n *}\right)=\frac{\beta\left[2 \beta\left(\alpha-c_{i}\right)-\gamma\left(\alpha-c_{j}\right)\right]^{2}}{\left(4 \beta^{2}-\gamma^{2}\right)^{2}}$.

In order to guarantee that the optimal decision-making of the manufacturers is meaningful under both conditions (with and without a cap-and-trade system), the model parameters should meet the conditions of $\frac{\gamma}{2 \beta}<\frac{\alpha-c_{i}-w e_{i}}{\alpha-c_{j}-w e_{j}}<\frac{2 \beta}{\gamma}$ and $\frac{\gamma}{2 \beta}<\frac{\alpha-c_{i}}{\alpha-c_{j}}<\frac{2 \beta}{\gamma} i, j=1,2$ and $i \neq j$. It can be seen that the model parameters must meet the condition of $\frac{\alpha-c_{j}}{w e_{j}}\left(\frac{\gamma}{2 \beta}-\frac{2 \beta}{\gamma}\right)+\frac{2 \beta}{\gamma}<\frac{e_{i}}{e_{j}}<\frac{\alpha-c_{j}}{w e_{j}}\left(\frac{2 \beta}{\gamma}-\frac{\gamma}{2 \beta}\right)+\frac{\gamma}{2 \beta}$, and this paper assumed the condition is tenable all the time.

By comparing the optimal decision-making of the manufacturers under the above two conditions, the following proposition can be obtained:

Proposition 5. (1) When $\frac{e_{i}}{e_{j}}>\frac{\gamma}{2 \beta}, q_{i}^{n *}>q_{i}^{c *}$; when $\frac{e_{i}}{e_{j}}=\frac{\gamma}{2 \beta}, q_{i}^{n *}=q_{i}^{c *} ;$ when $\frac{e_{i}}{e_{j}}<\frac{\gamma}{2 \beta}, q_{i}^{n *}<q_{i}^{c *}$.

(2) $p_{i}^{n *}<p_{i}^{c *}$. where, $i, j=1,2$ and $i \neq j$.

Prove. (1) $q_{i}^{n *}-q_{i}^{c *}=\frac{2 \beta w e_{i}-\gamma w e_{j}}{4 \beta^{2}-\gamma^{2}}$. When $\frac{e_{i}}{e_{j}}>\frac{\gamma}{2 \beta}, q_{i}^{n *}-q_{i}^{c *}>0$, namely $q_{i}^{n *}>q_{i}^{c *}$; similarly, when $\frac{e_{i}}{e_{j}}=\frac{\gamma}{2 \beta}, q_{i}^{n *}=q_{i}^{c *} ;$ when $\frac{e_{i}}{e_{j}}<\frac{\gamma}{2 \beta}, q_{i}^{n *}<q_{i}^{c *}$.

(2) Since $p_{i}^{c *}-p_{i}^{n *}=\frac{\left(2 \beta^{2}-\gamma^{2}\right) w e_{i}+\beta \gamma w e_{j}}{4 \beta^{2}-\gamma^{2}}>0$, then $p_{i}^{n *}<p_{i}^{c *}$.

Proposition 5 suggests that the production quantity of the two manufacturers is decided by their unit product carbon emission under a cap-and-trade system. If one manufacturer is obviously more competitive than its competitors in terms of the unit product carbon emission $\left(\frac{e_{i}}{e_{j}}<\frac{\gamma}{2 \beta}<0.5\right)$, the manufacturer's production quantity is increased after the government's implementation of the cap-and-trade system, which can finally contribute to the growth of its market shares. Proposition 5 also indicates that, no matter how large the gap is between the two manufacturers in terms of the unit carbon emission, the optimal price of the two manufacturers under a cap-and-trade system increases considerably compared with that without a cap-and-trade system.

Inference 1. When $\frac{\gamma}{2 \beta}<\frac{e_{i}}{e_{j}}<\frac{2 \beta}{\gamma}$, the production quantity of two manufacturers with a cap-and-trade system is smaller than that without the constraint; when $\frac{e_{i}}{e_{j}}>\frac{2 \beta}{\gamma}$, compared with the production quantity without a cap-and-trade system, the production quantity of $M_{i}$ and $M_{j}$ decreases and increases, respectively, under a cap-and-trade system; when $\frac{e_{i}}{e_{j}}<\frac{\gamma}{2 \beta}$, compared with the production quantity without a cap-and-trade system, the production capacity of $M_{i}$ and $M_{j}$ increases and decreases, respectively, under a cap-and-trade system.

Prove. The conclusion can be directly obtained from Proposition 5 .

Inference 1 suggests that the government's implementation of a cap-and-trade system can prompt enterprises with a low unit product carbon emission to produce more products to meet market demands but restrains enterprises with a high unit product carbon emission from increasing their production capacity. The carbon emission per unit product determines the output competition between manufacturers. Under the same market capacity and cap-and-trade system, the lower the carbon emissions per unit product, the lower the total cost per unit product, and the enterprise can win the market by increasing its production. All in all, the implementation of the cap-and-trade system has made the unit product carbon emission become an important index of enterprises' core competency. Enterprises with advanced techniques to cut their unit product carbon emission can be more competitive in the market. 
Proposition 6. When $A_{i}>\bar{A}_{i}, \pi_{i}^{c *}\left(q_{i}^{c *}, p_{i}^{c *}\right)>\pi_{i}^{n *}\left(q_{i}^{n *}, p_{i}^{n *}\right)$; when $A_{i}=\bar{A}_{i}, \pi_{i}^{c *}\left(q_{i}^{c *}, p_{i}^{c *}\right)=$ $\pi_{i}^{n *}\left(q_{i}^{n *}, p_{i}^{n *}\right)$; when $A_{i}<\bar{A}_{i}, \pi_{i}^{c *}\left(q_{i}^{c *}, p_{i}^{c *}\right)<\pi_{i}^{n *}\left(q_{i}^{n *}, p_{i}^{n *}\right)$.

Where $\bar{A}_{i} \equiv \frac{8 \beta^{3} e_{i}\left(\alpha-c_{i}-\frac{w e_{i}}{2}\right)-4 \beta^{2} e_{j} \gamma\left(\alpha-c_{i}-w e_{i}\right)-4 \beta^{2} e_{i} \gamma\left(\alpha-c_{j}\right)+2 \beta e_{j} \gamma^{2}\left(\alpha-c_{j}-\frac{w e_{j}}{2}\right)}{16 \beta^{4}+\gamma^{4}-8 \beta^{2} \gamma^{2}}$.

Prove. Subtract the maximum expected profits of the manufacturers under the two conditions to obtain

$$
\begin{aligned}
& \pi_{i}^{c *}\left(q_{i}^{c *}, p_{i}^{c *}\right)-\pi_{i}^{n *}\left(q_{i}^{n *}, p_{i}^{n *}\right) \\
& =\frac{\left(16 \beta^{4}+\gamma^{4}-8 \beta^{2} \gamma^{2}\right) A_{i}-8 \beta^{3} e_{i}\left(\alpha-c_{i}-\frac{w e_{i}}{2}\right)+4 \beta^{2} e_{j} \gamma\left(\alpha-c_{i}-w e_{i}\right)+4 \beta^{2} e_{i} \gamma\left(\alpha-c_{j}\right)-2 \beta e_{j} \gamma^{2}\left(\alpha-c_{j}-\frac{w e_{j}}{2}\right)}{\left(4 \beta^{2}-\gamma^{2}\right)^{2}}
\end{aligned}
$$

Assume that $\bar{A}_{i} \equiv \frac{8 \beta^{3} e_{i}\left(\alpha-c_{i}-\frac{w e_{i}}{2}\right)-4 \beta^{2} e_{j} \gamma\left(\alpha-c_{i}-w e_{i}\right)-4 \beta^{2} e_{i} \gamma\left(\alpha-c_{j}\right)+2 \beta e_{j} \gamma^{2}\left(\alpha-c_{j}-\frac{w e_{j}}{2}\right)}{16 \beta^{4}+\gamma^{4}-8 \beta^{2} \gamma^{2}}$.

When $A_{i}>\bar{A}_{i}$ and $\pi_{i}^{c *}\left(q_{i}^{c *}, p_{i}^{c *}\right)-\pi_{i}^{n *}\left(q_{i}^{n *}, p_{i}^{n *}\right)>0, \pi_{i}^{c *}\left(q_{i}^{c *}, p_{i}^{c *}\right)>\pi_{i}^{n *}\left(q_{i}^{n *}, p_{i}^{n *}\right)$.

Similarly, when

$$
A_{i}=\bar{A}_{i}, \pi_{i}^{c *}\left(q_{i}^{c *}, p_{i}^{c *}\right)=\pi_{i}^{n *}\left(q_{i}^{n *}, p_{i}^{n *}\right)
$$

when $A_{i}<\bar{A}_{i}, \pi_{i}^{c *}\left(q_{i}^{c *}, p_{i}^{c *}\right)<\pi_{i}^{n *}\left(q_{i}^{n *}, p_{i}^{n *}\right)$.

Proposition 6 suggests that, with the implementation of the cap-and-trade system, the increase of optimal profits of the manufacturers is decided by the correlation between the initial carbon emission quota granted by the government and the green production technological level (unit product carbon emission level) of the two manufacturers. When the initial carbon emission quota granted by the government is high $\left(A_{i}>\bar{A}_{i}\right)$, the optimal profits of the manufacturers after the implementation of the cap-and-trade system are higher than those before the application of the cap-and-trade system. The higher the government's initial carbon quota, the smaller the incentive for enterprises to invest in green technology, and the higher the carbon emission of the unit product. Therefore, in order to encourage enterprises to actively participate in green technology improvement and reduce the carbon emission of unit products, various factors regarding the enterprises need to be considered to establish the initial quota.

\section{Conclusions}

This paper studied how, under a cap-and-trade system, two manufacturers producing substitutable products conducted production, pricing, and carbon trading decision-making considering and not considering green technology investment. First, the optimal production quantity and the optimal price (and the optimal green technology investment if green technology investment is considered) of duopoly manufacturers under a cap-and-trade system was obtained by building and solving the game model. Second, by comparing the optimal decision-making and the maximum expected profits of duopoly manufacturers with and without a cap-and-trade system, this paper analyzed the influence of the cap-and-trade system on the optimal decision-making and the maximum expected profits of the cap-and-trade system on duopoly manufacturers, and obtained information beneficial for the optimization of the manufacturers' operational decision-making and of the government's formulation of carbon emission management policies. The study shows that the establishment of the initial carbon quota by the government is related to the level of investment in green technology by the enterprises, and that the carbon emission of unit products affects the market share of enterprises. In order to promote energy conservation and emission reduction, enterprises should pay more attention to the relationship between initial carbon quota and profit and to the relationship between carbon emission and output of unit products. The government should make more scientific carbon emission policies according to the situation of the enterprises.

Under a cap-and-trade system, this paper examined the issue of optimal decision-making of two manufacturers under the competitive environment. In real life, since the supply chain environment is more common, a study from the supply chain perspective will be more valuable. Besides, it would 
be better if a study could consider a supply chain environment consisting of two manufacturers and one retailer, discuss the optimal operational decision-making and supply chain coordination of the manufacturers and the retailer, explore how to further cut carbon emissions, and how to further optimize enterprise decision-making through supply chain coordination. Therefore, the authors will deepen this research by studying enterprise operational decision-making considering green technology investment, under a cap-and-trade system and from the perspective of the supply chain.

Acknowledgments: The authors would like to thank the editors and the anonymous reviewers for their insightful and constructive comments and suggestions that have led to this improved version of the paper. The work was supported in part by the Natural Science Foundation of Southwest University of Science and Technology (No. 15zx7139), the "Chunhui" Plan of Ministry of Education in China (No. S2011012 and No. Z2012017), the Key scientific research found of Xihua University (Grant No. Z1614417)), the Natural Science Foundation of education department of Sichuan (No. 17ZB0414), the National Natural Science Foundation of China (Grant No. 71702156), the MOE (Ministry of Education in China) Project of Humanities and Social Sciences (No. 17YJC630098).

Author Contributions: The research was designed and performed by Yi Zheng and Gaoxun Zhang. The data was collected by Weiwei Zhang. The analysis of the data was performed by Gaoxun Zhang. Finally, the paper was written by Yi Zheng, Gaoxun Zhang, and Weiwei Zhang. All authors read and approved the final manuscript.

Conflicts of Interest: The authors declare no conflict of interest.

\section{References}

1. Fang, J.Y.; Zhu, J.L.; Shi, Y. The responses of ecosystems to global warming. Chin. Sci. Bull. 2018, 63, $136-140$.

2. IPCC. Climate Change 2007: Comprehensive Report; IPCC: Geneva, Switzerland, 2007.

3. Song, J.; Leng, M. Analysis of the single-period problem under carbon emissions policies. In Handbook of Newsvendor Problems: International Series in Operations Research \& Management Science; Springer: New York, NY, USA, 2012; pp. 297-313.

4. Zhang, B.; Xu, L. Multi-item production planning with carbon cap and trade mechanism. Int. J. Prod. Econ. 2013, 144, 118-127. [CrossRef]

5. Zhang, R.; Liu, B.; Wang, W. Pricing decisions in a dual channels system with different power structures. Econ. Model. 2012, 29, 523-533. [CrossRef]

6. Shi, R.; Zhang, J.; Ru, J. Impacts of power structure on supply chains with uncertain demand. Prod. Oper. Manag. 2013, 22, 1232-1249. [CrossRef]

7. Xiao, T.J.; Choi, T.M.; Cheng, T.C.E. Product variety and channel structure strategy for a retailer-Stackelberg supply chain. Eur. J. Oper. Res. 2014, 233, 114-124. [CrossRef]

8. Zhao, D.Z.; Yuan, B.X.; Liang, J.; Xie, X.P. Dynamic Game Study in Supply China with Manufatures' Comprtition under the Constraint of Productions' Emission. Ind. Eng. Manag. China 2014, 19, 65-71.

9. Choi, S.C. Price competition in a channel structure with a common retailer. Mark. Sci. 1991, 10, $271-296$. [CrossRef]

10. Geffen, C.A.; Rothenberg, S. Suppliers and environmental innovation: The automotive paint process. Int. J. Oper. Prod. Manag. 2000, 20, 166-186. [CrossRef]

11. Klassen, R.D.; Vachon, S. Collaboration and evaluation in the supply chain: The impact on plant-level environmental investment. Prod. Oper. Manag. 2003, 12, 336-352. [CrossRef]

12. Vachon, S.; Klassen, R.D. Environmental management and manufacturing performance: The role of collaboration in the supply chain. Int. J. Prod. Econ. 2008, 111, 299-315. [CrossRef]

13. Moorthy, K.S. Product and price competition in a duopoly. Mark. Sci. 1988, 7, 141-168. [CrossRef]

14. Banker, R.D.; Khosla, I.; Sinha, K.K. Quality and competition. Manag. Sci. 1998, 44, 1179-1192. [CrossRef]

15. Wu, C.H.; Chen, C.W.; Hsieh, C.C. Competitive pricing decisions in a two-echelon supply chain with horizontal and vertical competition. Int. J. Prod. Res. 2012, 1, 265-274. [CrossRef]

16. So, K.C. Price and time competition for service delivery. Manuf. Serv. Oper. Manag. 2000, 2, 392-409. [CrossRef]

17. Chen, X.; Hao, G. Sustainable pricing and production policies for two competing firms with carbon emissions tax. Int. J. Prod. Res. 2014. [CrossRef]

18. Wu, Y.; Xiong, Z.K. Production strategies of the original equipment manufacturer and independent operator under the condition of competition. Syst. Eng. Theory Pract. China 2014, 346, 291-303. 
19. Hua, G.; Cheng, T.; Wang, S. Managing carbon footprints in inventory management. Int. J. Prod. Econ. 2011, 132, 178-185. [CrossRef]

20. He, P.; Zhang, W.; Xu, H.; Bian, Y. Production Lot-Sizing and Carbon Emissions under Cap-and-trade and Carbon Tax Regulations. J. Clean. Prod. 2014. [CrossRef]

21. Wahab, M.I.M.; Mamun, S.M.H.; Ongkunaruk, P. EOQ models for a coordinated two-level international supply chain considering imperfect items and environmental impact. Int. J. Prod. Econ. 2011, 134, 151-158. [CrossRef]

22. Xie, X.P.; Zhao, D.Z. Research on Cooperation Strategy of Enterprises' Carbon Emission Reduction on Low Carbon Supply Chain. J. Manag. Sci. China 2013, 26, 108-119.

23. Du, S.; Zhu, L.; Liang, L. Emission-dependent supply chain and environment-policy-making in the 'cap-and-trade' system. Energy Policy 2013, 57, 61-67. [CrossRef]

24. Tseng, S.C.; Hung, S.W. A strategic decision-making model considering the social costs of carbon dioxide emissions for sustainable supply chain management. J. Environ. Manag. 2014, 133, 315-322. [CrossRef] [PubMed]

25. Yalabik, B.; Fairchild, R.J. Customer, regulatory, and competitive pressure as drivers of environmental innovation. Int. J. Prod. Econ. 2011, 131, 519-527. [CrossRef]

26. Jiang, Y.; Klabjan, D. Optimal Emissions Reduction Investment under Green House Gas Emissions Regulations; Working Paper; Northwestern University: Evanston, IL, USA, 2012.

27. Toptal, A.; Özlü, H.; Konur, D. Joint decisions on inventory replenishment and emission reduction investment under different emission regulations. Int. J. Prod. Res. 2014, 52, 243-269. [CrossRef]

(C) 2018 by the authors. Licensee MDPI, Basel, Switzerland. This article is an open access article distributed under the terms and conditions of the Creative Commons Attribution (CC BY) license (http:/ / creativecommons.org/licenses/by/4.0/). 